\title{
Editorial: Cross-Disciplinary Marine Research: New Tools and Societal Interfaces
}

\author{
Daniel Rittschof ${ }^{1,2 *}$ \\ ${ }^{1}$ MSC Division, Nicholas School of the Environment, Duke University, Durham, NC, United States, ${ }^{2}$ Duke University Marine \\ Laboratory, Duke University, Beaufort, NC, United States
}

Keywords: drones law and conservation management, ocean acidification, shotgun proteomics, pollution, risk assessment, invasive species, turtle conservation, whale biomedicine

\section{Editorial on the Research Topic}

\section{Cross-Disciplinary Marine Research: New Tools and Societal Interfaces}

\section{OPEN ACCESS}

\section{Edited and reviewed by:} Marta Marcos,

University of the Balearic Islands, Spain

*Correspondence: Daniel Rittschof ritt@duke.edu

Specialty section:

This article was submitted to Coastal Ocean Processes,

a section of the journal

Frontiers in Marine Science

Received: 02 April 2021 Accepted: 13 April 2021 Published: 10 May 2021

Citation:

Rittschof D (2021) Editorial:

Cross-Disciplinary Marine Research: New Tools and Societal Interfaces.

Front. Mar. Sci. 8:690449.

doi: 10.3389/fmars.2021.690449
We support open access journals and transparent review as a way to broadly disseminate information and level the academic publishing playing field which, do to historical origins, supports more traditional siloed research more effectively than multidisciplinary research. There is plenty of room, necessity and extreme value in siloed research and multidisciplinary research and these terms are descriptive rather than pejorative. Our focus on New Tools and Societal Interfaces highlights multidisciplinary research that would generally get buried in the literature where it might not be readily accessed. Evaluation of multi-disciplinary research requires different ways of knowing, a difference in breadth of philosophy and culture and willingness to consider ways of knowing that are often foreign to existing disciplines. Each of the papers in this series crosses several boundaries, some of which seem minor and others of which are chasms. This was a bottom-up effort. All papers are related to societal issues but also generate knowledge for knowledge sake.

When one spends time working in multidisciplinary, cross and transdisciplinary research, the lines between disciplines blur. From the perspective of the practitioners it sometimes becomes difficult to recognize the standard disciplines and grasp that what is being done is actually unusual. This collection of 8 studies illustrates a few different ways of crossing traditional boundaries. It simultaneously illustrates the limitations of our personal communication networks and provides a point of entry for those considering a foray outside their comfort zone. If the authors of these papers can't answer your questions, it is likely that they know someone who can.

As editor, I, my coeditor and Frontiers made an effort to locate multidisciplinarians and encouraged them to apply for this special issue. Of the eight papers accepted, six were through professional relationships, and two were through Frontiers advertising. All eight papers sit in the gap between applied and basic research.

It is telling that six of the eight papers are related to conservation and six are related through living resource management. The two papers not related to conservation or to management are one report of research moving from applied studies toward theory and one report moving from basic research toward applied research.

When it comes to technology, drones are a really hot topic. It is not surprising that three of our eight papers address drone technology. These three papers provide context and entry to a vast 
literature and evolving technology network. As drones take their place in our scientific toolbox, ethics, legal questions and questions about drone impacts on animal behavior and sharing of expertise and equipment inevitably will come to the fore.

Nowlin et al. address human behavior on the coasts and take an interesting look at human privacy concerns. Although the legal scholarship is directly related to the 4th amendment of the US Constitution, the concerns, arguments and logical structure can be used to think about drones and human privacy issues anywhere. I was left with a good understanding of US issues and concerns and curiosity about the use of drones and human activities in other societies.

Horton et al., expands Drone use to biomedicine for whales. An engaging story of mother and calf is a breath of fresh air with respiration rates and fin hotspots and the mothers heart beat and punctuated with honest looks at permits, laws, limitations and expensive science. There is little doubt that the techniques described will be improved and used to enhance our understanding of free ranging megafauna. UAV researchers are masters at mathematical manipulation. I was surprised that the drone did not appear to disrupt whale behavior and how quickly the mother daughter pair picked up an observation boat.

Complementing the pricey Dr Drone work (Windle et al.), use an inexpensive drone that provides a rapid, turtles eye view of photo-pollution on turtle nesting beaches. This drone is turtle safe, and the data can help inform managers involved in policy for turtle nesting management. Drone data support hypotheses about light pollution and turtle nesting and a tireless and less invasive tool to provide information that can be used by researchers and managers.

Once you have a sea turtle nest, and after an incubation period, the hatchlings must dig out and get back to the ocean. Erb and Wyneken et al. treat us to details of that perilous journey. I was consoled by the fact that the major predator, ghost crabs can't capture that many turtles. Simultaneously, I was depressed by the impacts of coastal urbanization and photo-pollution on nest and hatchling success. There is nothing worse than getting lost on what should be a dangerous but short journey. As I read this paper, I thought how valuable combining Erb and Wyneken et al. studies with Windle et al. technology might be for emergence and survival studies and improving information used in management.

In addition to drones, other relatively new technologies diffuse to marine biology and drive new multidisciplinary efforts. High resolution mass spectrometry is a technology that was first used in marine natural products chemistry and is now slowly making its mark on other kinds of marine biology. The example in this series is Essock-Burns et al. who use high resolution mass spectrometry, barnacles and knowledge of the proteomics of the evolutionarily ancient innate immune response to take a fresh look at biological glue curing. The authors put barnacle glue curing in the context of the innate immune response. I gained perspective on how biological glues cure and just how messy biological systems can be. My three take homes were: (1) reactive oxygen species are central to glue crosslinking; (2) any and all inorganic and organic oxidative chemistries can be involved; and
(3) High resolution mass spectrometry is an amazing tool that is ideal for providing perspective in complex chemical systems.

Although chemistry and natural products chemistry have long histories in marine and environmental research, biochemistry is less well-represented. Enzyme remediation is being explored with respect to toxic and persistent plastic waste. The paper by Sheth et al. makes a case for enzyme prospecting similar to the prospecting that is done for natural product pharmaceuticals. The paper provides a great overview of plastic and plastic pollution and a stark picture of the tip of the global iceberg that is plastic waste, its environmental hazards and carcinogenicity of components. This might be one of the first papers a protein engineer or waste management engineer interested in research on remediation of plastic waste might read. I was intrigued by the acknowledgment that the generation of refractory polymers needs to stop and that once these long lived polymers are no longer being delivered that we will still have trillions of kilograms of plastic waste that still must be remediated.

Many government agencies do a large amount of societally relevant and ecologically important research which is generally presented in a data rich format that hard for most marine researchers to find and to digest. In our series we have two examples of research that is embedded in ocean processes that relate directly to man's activity.

Scianni and Georgiades et al. combine biofouling, biosecurity, invasive species, toxic pollutants and policy. This New Zealand and American duo graciously acquiesced to an offering that is almost like dessert. The technology, in water vessel cleaning, seems simple, has few global environmental ramifications if done correctly, but huge impacts if done incorrectly. It is interesting that a technology that costs thousands of dollars per vessel, if done at the right time and in the right place, saves many more thousands of dollars. Correct hull management can dramatically reduce the biosecurity risk of invasive species, toxic chemical release and result in reduced greenhouse gas emissions. As an outsider I found myself thinking about how breakthroughs are accomplished in areas like these and how important multidisciplinary knowledge is to the formulation of science based environmental policy.

Bednarsek et al. is a global effort by like-minded individuals working with pteropods, pelagic snails, with known sensitivity to ocean acidification and aragonite saturation state. The authors would use calcified pteropods as canaries in the coalmine for ocean acidification. Meta-analysis is combined with biogeochemical modeling and then qualitative modification by experts to provide insight on the most sensitive measure and life stage to provide guidance for managers. Once again I was humbled by what I don't know, in this case, impacts of multiple stressors, even two stressors, temperature and OA. I was excited by the approach and modeling off the central California coast. Now I'm curious about the impact of coastal environmental history on responses of marine calcifiers in warm temperate waters with a geological history of excursions to low $\mathrm{pH}$ and lower aragonite saturation states. 


\section{AUTHOR CONTRIBUTIONS}

DR generated this piece after enjoying reading the papers in the series.

\section{ACKNOWLEDGMENTS}

I thank the authors and reviewers for their combined efforts to help maximize the impact of the articles. Thanks to James Scott Maki who contributed to the Research Topic. Everyone walked the walk!
Conflict of Interest: The author declares that the research was conducted in the absence of any commercial or financial relationships that could be construed as a potential conflict of interest.

Copyright (๑) 2021 Rittschof. This is an open-access article distributed under the terms of the Creative Commons Attribution License (CC BY). The use, distribution or reproduction in other forums is permitted, provided the original author(s) and the copyright owner(s) are credited and that the original publication in this journal is cited, in accordance with accepted academic practice. No use, distribution or reproduction is permitted which does not comply with these terms. 